\title{
Absorption Properties of the Carotenoids after Alkaline Denaturation of the Light-Harvesting Complex II from Ectothiorhodospira sp.
}

\author{
André Buche* and Rafael Picorel \\ Estación Experimental de Aula Dei (CSIC), Apartado 202, E-50080 Zaragoza, Spain. \\ Fax: 34-976-575620. E-mail: abuche@eead.csic.es \\ * Author for correspondence and reprint requests \\ Z. Naturforsch. 55c, 576-581 (2000); received February 25/April 4, 2000 \\ Carotenoid, Soret, Shift, Spirilloxanthin
}

Alkaline treatment of the Ectothiorhodospira sp. light harvesting system II induces monomerisation of the bacteriochlorophylls and a bleaching of the carotenoid absorption bands in the visible region. Concomitantly, the maximum of absorption observed around $373 \mathrm{~nm}$ shifts towards $354 \mathrm{~nm}$. This shift does not result from the Soret band but from a change of the absorption properties of the carotenoids. Furthermore, these pigments are not modified chemically but the spectral conversion results from environmental changes. It is assumed that the dissociation of the bacteriochlorophylls in alkaline medium is accompanied by a structural reorganisation of the complex which reinforces the interactions between the polypeptides and the carotenoids.

\section{Introduction}

In photosynthesis, light is absorbed by the pigment-protein antenna complexes and the corresponding excitation energy transferred to the pigment-protein reaction center complexes within the photosynthetic membranes (Sundström and van Grondelle, 1996). Three different types of antenna complexes can be isolated from purple photosynthetic bacteria. The LHI or B880 (Cogdell, 1986; Picorel and Gingras, 1988; Sundström and van Grondelle, 1996) is present in all purple bacteria and remains intimately associated with the reaction center. This antenna is present in all photosynthetic bacteria. The LHII or B800-850 (Clayton and Clayton, 1979; Feick and Drews, 1978; Picorel et al., 1984; Walker et al., 1988; Doi et al., 1991) and LHIII or B800-820 (Hayashi and Morita, 1980; Cogdell et al., 1983) are arranged more peripherally (Monger and Parson, 1977). Their concentration in the cells can vary with growth conditions. All of these antenna complexes are spectrally characterized by one or two strong near

Abbreviations: Bchl, Bacteriochlorophyll; LH, Lightharvesting; B800, bacterichlorophylls that absorb around $800 \mathrm{~nm} ; \mathrm{B} 850$, bacteriochlorophylls that absorb around $850 \mathrm{~nm}$; Lys, lysine. infrared electronic absorption bands arising from the $\mathrm{Q}_{\mathrm{y}}$ transition of the bacteriochlorophyll (Bchl) $a$. The LHII has two bands around 800 (B800) and 850 (B850) $\mathrm{nm}$ in its native state (Cogdell, 1986). The crystal structure of the LHII complex from Rhodopseudomonas (Rps.) acidophila (McDermott et al., 1995) and Rhodospirillum (Rs.) molischianum (Koepke et al., 1996) were established. The active assembly consists of two concentric cylinders of $9 \alpha / 9 \beta$ helical protein subunits in Rps. acidophila or $8 \alpha / 8 \beta$ in Rs. molischianum which hold the pigment molecules. Eighteen or sixteen Bchls (depending on the species) are sandwiched between the protein helices near the periplasmic side of the cytoplasmic membrane and another set of nine or eight Bchls (depending on the species) are positioned towards the cytoplasmic side. The Bchls absorbing around $850 \mathrm{~nm}$ are excitonically coupled in all photosynthetic bacteria. The Bchls absorbing around $800 \mathrm{~nm}$ are normally non-excitonically coupled (Fowler et al., 1992). In certain cases, however, as with Rps. palustris (van Mourik et al., 1992), Rs. molischianum (Visschers et al., 1995) and Ectothiorhodospira sp. (Buche and Picorel, 1998) these Bchls seem to be excitonically coupled based on circular dichroism (CD) data. The $\mathrm{Q}_{\mathrm{x}}$ transitions present a band around $590 \mathrm{~nm}$. Towards $373 \mathrm{~nm}$, the BxBy transitions generate the "Soret band".
This work has been digitalized and published in 2013 by Verlag Zeitschrif für Naturforschung in cooperation with the Max Planck Society for the Advancement of Science under a Creative Commons Attribution-NoDerivs 3.0 Germany License.

On 01.01.2015 it is planned to change the License Conditions (the remova of the Creative Commons License condition "no derivative works"). This is to allow reuse in the area of future scientific usage. 
Another class of pigments which contributes to the structure of the light harvesting complexes is the carotenoid (McDermott et al., 1995; Koepke et al., 1996). Generally, the presence of this class of compounds in the LHII complex is easily detected by its absorbance in the visible region (see for example Fowler et al., 1997). However, the carotenoid can strongly absorb in the $340-400 \mathrm{~nm}$ region depending on the type, the medium, or on the chemical modification (Boucher et al., 1977; Truscott, 1990). Depending on the species, a lightharvesting complex may contain several types of carotenoids. The LHII complex of Ectothiorhodospira sp. contains spirilloxanthin as the major carotenoid (Ortiz de Zarate, 1995).

Recently, we have investigated the spectral modifications of the LHII Bchls in the presence of high concentrations of $\mathrm{NaOH}$ (in preparation). In the present work, it was observed that this process is accompanied by a shift of the absorbance maximum from 373 to $354 \mathrm{~nm}$ which would arise from a conversion of the absorption properties of the carotenoids.

\section{Materials and Methods}

\section{LHII complex preparation}

Ectothiorhodospira sp. was grown photosynthetically as described by Lefebvre et al. (1984). Preparations of the LHII antenna complex were obtained as described previously (Ortiz de Zarate and Picorel, 1994) with some modifications (Buche and Picorel, 1998).

\section{Sample preparation}

Highly concentrated solutions of LHII antenna complex were diluted into $1 \mathrm{ml}$ of $10 \mathrm{~mm}$ (tris[hydroxymethyl]aminomethane)-HCl (Tris- $\mathrm{HCl}$ ) buffer or adequate $\mathrm{NaOH}$ solutions. Final $\mathrm{NaOH}$ concentration was 9 м. Final sample concentrations corresponded to $0.4-0.6$ absorption units measured at the B800 band. The reversion experiments were carried out first by a 10 fold dilution with $10 \mathrm{~mm}$ Tris- $\mathrm{HCl}, \mathrm{pH} 8$. The sample was then neutralised either by dialysis against $10 \mathrm{~mm}$ Tris$\mathrm{HCl}, \mathrm{pH} 8$ or by injecting $\mathrm{HCl}$ directly into the LHII complex- $\mathrm{NaOH}$ solutions.

\section{Spectroscopic measurements}

Absorption spectra were performed by a Beckman DU-640 spectrophotometer at room temperature under $1 \mathrm{~cm}$ pathlength. Results reproducibility was verified 3 times. For the analysis of the spectra the GRAMS software (Galactic Industries Co., Salem, NH) was used.

\section{Pigment extraction}

Pigments were extracted with an acetone/methanol (7/2, v/v) mixture. After sample sonication for $1 \mathrm{~min}$, the extract was centrifuged in a microfuge for $2 \mathrm{~min}$ to pellet the undissolved material and the supernatant recovered for further analyses.

\section{HPLC analysis}

The extracted pigments were analyzed by HPLC basically as in Evans et al. (1988) using the System Gold (Beckman Instrument) equipped with a diode-array detector 168. Pigment separation was achieved with a reversed phase column $(25 \times 0.46$ $\mathrm{cm})$ (Beckman Ultrasphere ODS $5 \mathrm{~mm}$ ). A linear gradient of $0-100 \%$ solvent B (ethyl acetate) and $100-0 \%$ solvent A (90\% acetonitrile/water, $0.5 \%$ triethylamine) was used at a flow rate of $1 \mathrm{ml} / \mathrm{min}$ over $25 \mathrm{~min}$.

\section{Results}

The denaturation effect of $9 \mathrm{~m} \mathrm{NaOH}$ on the LHII complex is presented in Figure 1A. After 90 min treatment the carotenoid absorption bands in the 430-550 nm spectral region disappeared completely and the $\mathrm{Q}_{\mathrm{x}}$ band of the Bchls blueshifted from 590 to $569 \mathrm{~nm}$. This corresponded to the monomerisation of the B800 and B850 Bchls (not shown). After 6 min of alkaline treatment a reduction of the Soret band intensity was observed and between 6 and 90 min the absorbance around $354 \mathrm{~nm}$ reappeared. At a first glance one could assume that the Soret band has blueshifted from 373 to $354 \mathrm{~nm}$. However, the second derivatives of the absorption spectra (Fig. 1B) suggest that the Soret band, although decreased in intensity, is maintained around $373 \mathrm{~nm}$ whereas the 354 band could be generated by the carotenoids.

As shown in Fig. 2, the reversion at $\mathrm{pH} 8.0$ was analysed: After a 90-min alkaline treatment of the LHII complex, the sample was diluted tenfold and 

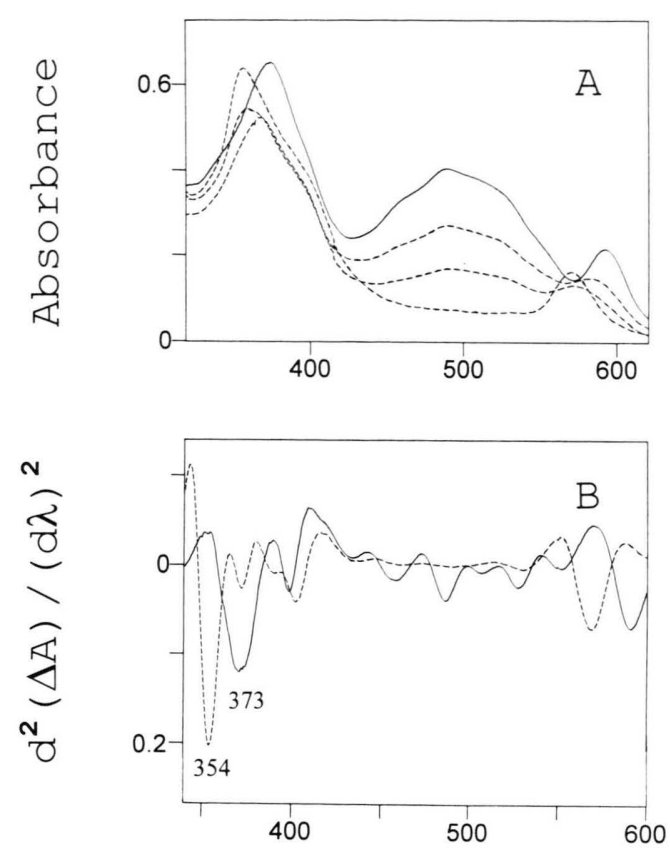

Wavelength $(\mathrm{nm})$

Fig. 1. A. Effect of different time of $9 \mathrm{~m} \mathrm{NaOH}$ exposure on the LHII spectral properties from 300 to $620 \mathrm{~nm}$ : $0 \mathrm{~min}$ (solid line), 6, 30, and $90 \mathrm{~min}$, respectively (dashed line).

B. Second derivative of the LHII spectra without (solid line) and after $90 \mathrm{~min}$ of $\mathrm{NaOH}$ exposure (dashed line).

then neutralised to $\mathrm{pH}$ 8.0. The $\mathrm{Q}_{\mathrm{x}}$ band disappeared completely, just as the $\mathrm{Q}_{\mathrm{y}}$ bands (not show). The second derivative confirms the removal of the Soret band as well as the bands located between 389 and $402 \mathrm{~nm}$ which possibly resulted from Bchl degradation (Ortiz de Zarate, 1995). On the other hand, the $354 \mathrm{~nm}$ band remains, its maximum being 3-nm redshifted. In order to check which pigments are responsible for the absorption changes, the pigments of the reverted sample were extracted with an acetone/ methanol (7/2) mixture and compared with the pigments of an untreated (control) LHII complex (Fig. 3A,B). Pigments of both treated and untreated samples show the same carotenoid bands in the VIS region. This indicates that the $354 \mathrm{~nm}$ band of Fig. 1 does not result from a shift of the Bchl Soret band but from a conversion of the carotenoid bands. However, the HPLC runs of these
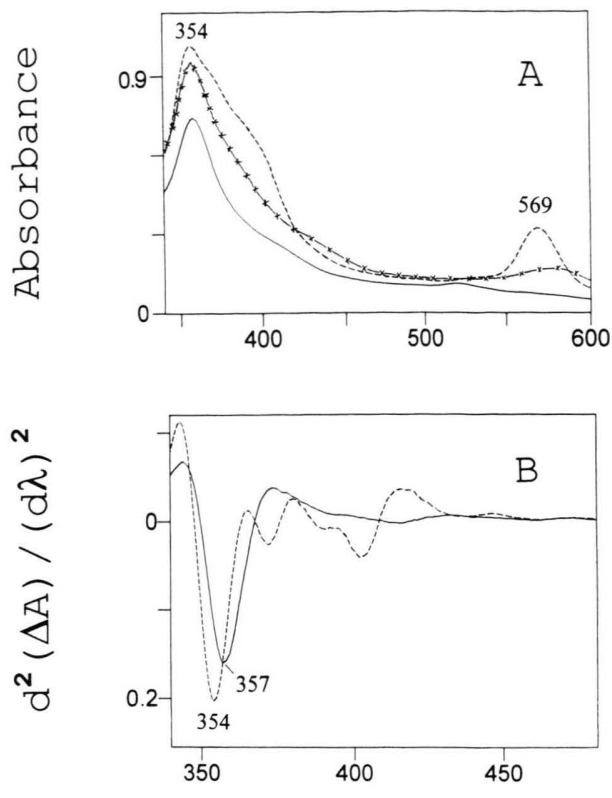

Wavelength ( $\mathrm{nm}$ )

Fig. 2. Effect of the reversion from $9 \mathrm{~m} \mathrm{NaOH}$ (dashed line) to $0.9 \mathrm{M} \mathrm{NaOH}$ by dilution (cross line) and from 0.9 м $\mathrm{NaOH}$ to $\mathrm{pH} 8$ by $\mathrm{HCl}$ addition (solid line).

A. Spectra from 340 to $600 \mathrm{~nm}$. The curves were corrected for the dilution effect.

B. Corresponding second derivatives.

two samples were practically identical (Fig. 4) proving that the carotenoids were not modified chemically by the alkaline treatment.

\section{Discussion}

Recently, we performed a study focused on the effect of various alkaline treatments on the LHII complex of Ectothiorhodospira sp. Using high $\mathrm{NaOH}$ concentration, we observed that it was very difficult to denature this complex; i. e., up to $1.5 \mathrm{~m}$ $\mathrm{NaOH}$ the only effect on the absorption spectrum was a reversible blueshift of the B850 which we ascribed to a Lys deprotonation (Buche and Picorel, 1998). The monomerisation of the Bchls was induced using a $\mathrm{NaOH}$ concentration higher than $4 \mathrm{~m}$. Concomitantly to the Bchl monomerisation some other spectral modifications appear as a bleaching of the carotenoid bands in the 400$550 \mathrm{~nm}$ spectral region. The question arises whether the carotenoids are destroyed or there is only a band shift phenomenon. And also is the 

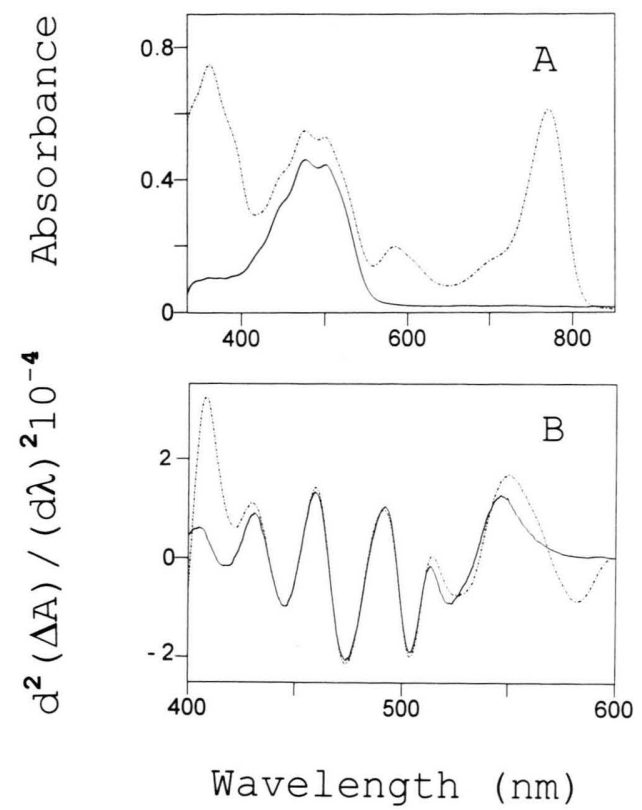

Fig. 3. Pigments extract in acetone/methanol (7/2) of the LHII complex without (dash-dot) or after $90 \operatorname{min~} \mathrm{NaOH}$ exposure and neutralisation to $\mathrm{pH} 8$ by $\mathrm{HCl}$ addition (solid).

A. Spectra from 340 to $830 \mathrm{~nm}$.

B. Second derivatives from 400 to $600 \mathrm{~nm}$. absorption maximum shifting from $373 \mathrm{~nm}$ to $354 \mathrm{~nm}$ the result of a shift of the Bchl Soret band? The spectra presented in the Fig. 1 indicate that the Bchl Soret band is maintained around $373 \mathrm{~nm}$ and there is a correlation between the disappearance of the carotenoid bands in the $400-550 \mathrm{~nm}$ spectral region and the appearance of the $354 \mathrm{~nm}$ band. In addition, after neutralisation of $\mathrm{NaOH}$, the band at $354 \mathrm{~nm}$ is practically the only one to remain while the Bchls signals disappear. It should be recalled that in aqueous medium the (B)chl normally cannot stay in its monomeric state. For example, under certain experimental conditions Bchl $a$ aggregates giving both circular dichroism and absorption spectra (Scherz et al., 1991; Uehara, et al., 1995) most similar to those of type II chlorosomes (Somsen and van Grondelle, 1996). In the present work, the maintenance of the monomeric form in aqueous solution seems to be directly related to the presence of a high $\mathrm{NaOH}$ concentration. Neutralising the solution seems to induce a total and irreversible loss of solubility. The mechanism of Bchl $a$ self-assembly in aqueous media can be considered as a manifestation of the Hofmeister effect (Koynova et al., 1997; Vladkova, 2000). It relates to the (co)solvent ability to distribute water in the vicinity of the macromolecule.
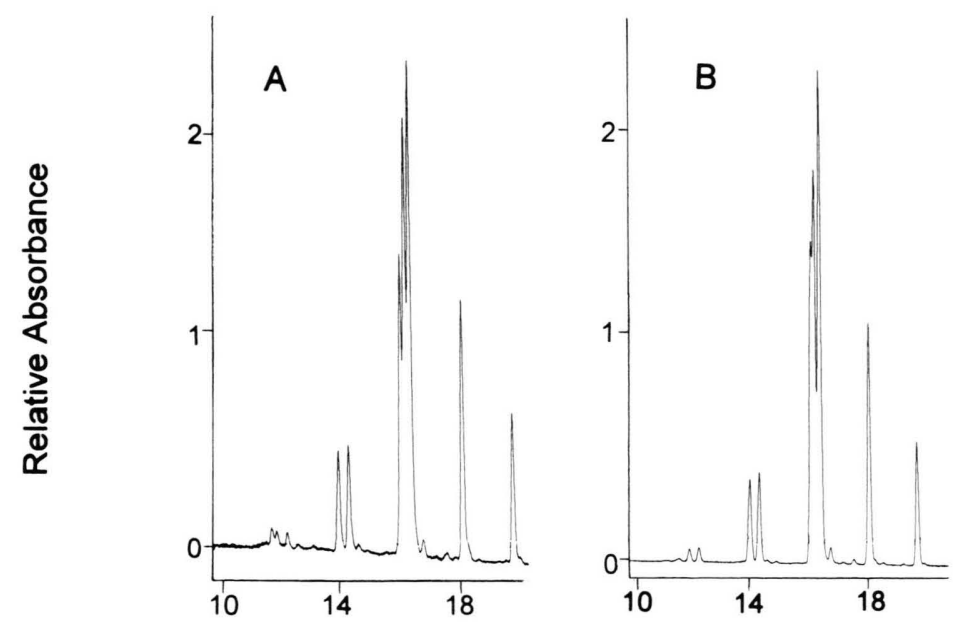

\section{Retention Time ( $\mathrm{min})$}

Fig. 4. HPLC pigment extract chromatograms detected at $485 \mathrm{~nm}$ from untreated LHII complex (A) and treated/ reverted complex (B). 
Analysis of treated sample pigments reveals only the presence of carotenoids. This clearly states that the $354 \mathrm{~nm}$ band is due to these pigments. Moreover, the HPLC study indicates that both treated and native samples have the same carotenoid composition. Thus, the carotenoid band shifts from $400-550 \mathrm{~nm}$ region towards $354 \mathrm{~nm}$ cannot be explained by a chemical modification of these pigments. This phenomenon thus results from an effect of the environment similar to that previously reported for spirilloxanthin in the photoreaction center of Rs. rubrum (Boucher et al., 1977). Differential spectra studies of both wildtype and carotenoid-less mutants show that when spirilloxanthin is attached to the complex, it absorbs relatively more in the $340-400 \mathrm{~nm}$ region $\left({ }^{1} \mathrm{C} \rightarrow{ }^{1} \mathrm{~A}\right.$ transitions) than in the visible region $\left({ }^{1} \mathrm{~B}\right.$ $\rightarrow{ }^{1} \mathrm{~A}$ transitions). On the other hand, if the spirilloxanthin is dispersed in organic or aqueous solution this ratio is markedly reversed. In the present work, apparently the Bchl dissociation by $\mathrm{NaOH}$ induces a strengthening of the interactions between the protein matrix and the carotenoids.

Boucher F., van der Rest M. and Gingras G. (1977), Structure and function of carotenoids in the photoreaction center from Rhodospirillum rubrum, Biochim. Biophys. Acta 461, 339-357.

Buche A. and Picorel R. (1998), Spectral changes induced by alkaline $\mathrm{pH}$ and specific chemical modification of amino acid residues in the light-harvesting II antenna complex from Ectothiorhodospira sp. Photochem. Photobiol. 69, 275-281.

Clayton R. K. and Clayton B. J. (1979), B850 pigmentprotein complex of Rhodopseudomonas sphaeroides extinction coefficients, circular dichroism, and the reversible binding of bacteriochlorophyll. Proc. Natl. Acad. Sci. USA 78, 5583-5587.

Cogdell R. J. (1986), Light-harvesting complexes in the purple bacteria. In: Encyclopaedia of Plant Physiology, Photosynthesis, III vol. 19 (Staehelin, L. A. and Arntzen, C. J., eds). Springer Publ., Berlin, pp. 252-259.

Cogdell R. J., Y. Durant Y., Valentine Y., Lindsay J. G. and Schmidt K. (1983), The isolation and partial characterization of the light-harvesting pigment-protein complement of Rhodopseudomonas sphaeroides. Biochim. Biophys. Acta 722, 427-435.

McDermott G., Prince S. M., Freer A. A., Hawthornthwaite-Lawless A. M., Papiz M. Z., Cogdell R. J. and Isaacs N. W. (1995), Crystal structure of an integral membrane light harvesting complex from photosynthetic bacteria. Nature 374, 517-521.
When a sample is neutralized by $\mathrm{HCl}$ or dialysis (see Materials and Methods) identical results are obtained: the $354 \mathrm{~nm}$ band is always accompanied by a band around $280 \mathrm{~nm}$ in a constant proportion (not shown). This may indicate that the carotenoids remain in contact with the protein matrix throughout the alkaline treatment.

In conclusion, the emergence of a band around $354 \mathrm{~nm}$ during the alkaline treatment does not result from a shift of the Bchl Soret band but rather from a change of the spectral properties of the carotenoids (primarily spirilloxanthin) resulting from modifications of the environment of these pigments. The new properties of the carotenoids suggest a reinforcement of the binding of these pigments to the protein matrix.

\section{Acknowledgements}

I would like to thank María V. Ramiro for skilful technical assistance. The work was supported by the EC contract CT93-0278 and the DGICYT (Grant PB98-1632).

Doi M., Y. Shioi N., Gad'on J. R. Golecki and G. Drews (1991), Spectroscopical studies on the light-harvesting pigment-protein complex II from dark-aerobic grown cells of Rhodobacter sulfidophilus. Biochim. Biophys. Acta 1058, 235-241.

Evans M. B., Cogdell R. J. and Britton G. (1988), Determination of the bacteriochlorophyll: carotenoid ratios of the B890 antenna complex of Rhodospirillum rubrum and the B800-850 complex of Rhodobacter sphaeroides, Biochim. Biophys. Acta 935, 292-298.

Feick R. and G. Drews (1978), Isolation and characterization of light harvesting bacteriochlorophyll-protein complexes from Rhodopseudomonas capsulata. Biochim. Biophys. Acta 501, 499-513.

Fowler G. J. S., Visschers R. W., Grief C. G., van Grondelle R. and Hunter C. N. (1992), Genetically modified photosynthetic antenna complexes with blueshifted absorbance bands. Nature 355, 848-850.

Fowler G. J. S., Hess S., Pullerits T., Sundstrom V. and Hunter C. N. (1997), The role of betaArg-10 in the B800 bacteriochlorophyll and carotenoid pigment environment within the light-harvesting LH2 complex of Rhodobacter sphaeroides. Biochemistry 36, 1128211291.

Koepke J., Hu X., Muenke C., Schulten K. and Michel H. (1996), The crystal structure of the light-harvesting complex II (B800-850) from Rhodospirillum molischianum. Structure 4, 581-597. 
Koynova R., Brankov J. and Tenchov B. (1997), Modulation of the lipid phase behaviour by kosmotropic and chaotropic solutes. Experiment and thermodynamic theory. Eur. Biophys. J. 25, 261-274.

Monger T. G. and Parson W. W. (1977), Singlet-triplet fusion in Rhodopseudomonas sphaeroides chromatophores. A probe of the organization of the photosynthetic apparatus. Biochim. Biophys. Acta 460,393-407.

van Mourik F., Hawthornthwaite A. M., Vonk C., Evans M., Cogdell R. J., Sundström V. and van Grondelle R. (1992), Spectroscopic characterization of the low-light B800-850 light-harvesting complex of Rhodospeudomonas palustris, strain 2.1.6. Biochim. Biophys. Acta 1140, 85-93.

Ortiz de Zarate I. (1995), Estudio estructural de las antenas de bacterias purpuras mediante técnicas espectroscópicas. Doctoral Thesis, University of Zaragoza.

Ortiz de Zarate I. and R. Picorel (1994), Spectral changes of the B800-850 antenna complex from Ectothiorhodospira $s p$. induced by detergent and salt treatment. Photosynth. Res. 41, 339-347.

Picorel R. and Gingras G. (1988), Preparative isolation and characterization of the B875 complex from Rhodobacter sphaeroides 2.4.1. Biochem. Cell Biol. 66, $442-448$.

Picorel R., S. Lefebvre and G. Gingras (1984), Oxidoreduction of $\mathrm{B} 800-850$ and $\mathrm{B} 880$ holochromes isolated from three species of photosynthetic bacteria as studied by electron paramagnetic resonance and optical spectroscopy. Eur. J. Biochem. 142, 305-311.

Scherz A., Rosenbach-Belkin V. and Fisher J. R. E. (1991), Chlorophyll aggregation in aqueous solutions.
In: Chlorophylls (Scheer H. ed.). CRC Press, Boca Raton, FL, pp. 237-268.

Somsen J. G., van Grondelle R. and van Amerongen H. (1996), Spectral broadening of interacting pigments: Polarized absorption by photosynthetic proteins. Biophysical J. 71,1934-1951.

Sundström V. and van Grondelle R. (1996), Kinetics of excitation transfer and trapping in purple bacteria. In: Anoxygenic Photosynthetic Bacteria, (Blankenship, R., Madigan, M. T. and Bauer, C. E., ed.). Kluwer Academic Publishers, Dordrecht, The Netherlands, pp. 349-372.

Truscott T. G. (1990), The photophysics and photochemistry of the carotenoids. J. Photochem. and Photobiol. B 6, 359-371.

Uehara K., Ishii T. and Mimuro M. (1995), pH effect on the supramolecular assemblies of bacteriochlorophyll aggregates in aquous organic media. In: Photosynthesis: from Light to Biosphere, Vol. 1 (Mathis P., ed.). Dordrecht: Kluwer Academic Publ., pp. 267-270.

Visschers R. W., Germeroth L., Michel H., Monshouwer R. and van Grondelle R. (1995), Spectroscopic properties of the light-harvesting complexes from Rhodospirillum molischianum. Biochim. Biophys. Acta 1230, $147-154$.

Vladkova R. (2000), Chlorophyll a self-assembly in polar solvent-water mixtures. Photochem. Photobiol. 71, $71-83$.

Walker T., Gad'on N., Steck K., Welte W. and Drews G. (1988), Isolation of reaction center and antenna complexes from the halophilic purple bacterium Rhodospirillum salexigens. Biochim. Biophys. Acta 933, 299-305. 